of a thorough predischarge checkup after transcatheter aortic valve implantation even in symptom-free patients.

\section{References}

1. Himbert D, Descoutures F, Al-Attar N, Iung B, Ducrocq G, Détaint D, et al. Results of transfemoral or transapical aortic valve implantation following a uniform assessment in high-risk patients with aortic stenosis. J Am Coll Cardiol. 2009;54: 303-11.
2. Attias D, Himbert D, Hvass U, Vahanian A. "Valve-in-valve" implantation in a patient with stentless bioprosthesis and severe intraprosthetic aortic regurgitation. $J$ Thorac Cardiovasc Surg. 2009;138:1020-2.

3. Clavel MA, Dumont E, Pibarot P, Doyle D, De Larochellière R, Villeneuve $\mathbf{J}$, et al. Severe valvular regurgitation and late prosthesis embolization after percutaneous aortic valve implantation. Ann Thorac Surg. 2009; $87: 618-21$.

4. Maroto LC, Rodriguez JE, Cobiella J, Silva J. Delayed dislocation of a transapically implanted aortic bioprosthesis. Eur J Cardiothorac Surg. 2009;36: 935-7.

\title{
Pulmonary vein thrombosis after video-assisted thoracoscopic left upper lobectomy
}

\author{
Kazuto Ohtaka, MD, Yasuhiro Hida, MD, PhD, Kichizo Kaga, MD, PhD, Yasuaki Iimura, MD, PhD, \\ Nobuyuki Shiina, MD, Jun Muto, MD, and Satoshi Hirano, MD, PhD, Sapporo, Japan
}

Thrombus in the stump of the pulmonary vein (PV) after lung resection is a rare but lethal complication. Only 3 case reports have described radiographically detected thrombus in the stump of the PV. ${ }^{1-3}$ Thrombus in the systemic circulation can result in infarction of the brain, kidneys, and spleen. We describe 3 patients with thrombus in the stump of the PV after video-assisted thoracoscopic left upper lobectomy.

\section{CASE REPORTS \\ Patient 1}

A shadow was evident in the left upper lung field in the routine screening chest x-ray of a 64-year-old woman who was a nonsmoker with a medical history of chronic atrial fibrillation. Chest computed tomography (CT) showed a mass $31 \mathrm{~mm}$ in diameter in the left upper lobe. A transbronchial lung biopsy (TBLB) demonstrated adenocarcinoma. She underwent left upper lobectomy with systematic lymph node dissection using video-assisted thoracoscopic surgery. The left superior pulmonary vein (LSPV) was divided using a linear stapler at the point where it branched to the superior segment, and the branch to the lingular segment was ligated and divided. The

\footnotetext{
From the Division of Cancer Medicine, Department of Surgical Oncology, Hokkaido University Graduate School of Medicine, Sapporo, Japan.

Disclosures: Authors have nothing to disclose with regard to commercial support.

Received for publication July 11, 2011; revisions received Aug 8, 2011; accepted for publication Sept 21, 2011; available ahead of print Oct 19, 2011.

Address for reprints: Yasuhiro Hida, MD, PhD, Department of Surgical Oncology, Division of Cancer Medicine, Hokkaido University Graduate School of Medicine, North 15, West 7, Kita-ku, Sapporo 060-8638, Japan (E-mail: yhida@med. hokudai.ac.jp).

J Thorac Cardiovasc Surg 2012;143:e3-5

$0022-5223 / \$ 36.00$

Copyright (c) 2012 by The American Association for Thoracic Surgery doi:10.1016/j.jtcvs.2011.09.025
}

postoperative course was uncomplicated. She was prescribed oral tegafur/uracil as adjuvant chemotherapy and followed up every 6 months. Enhanced CT showed a thrombus in the stump of the LSPV 19 months postoperatively (Figure 1, A). Anticoagulant therapy was immediately started, and CT 24 months postoperatively showed that the thrombus had disappeared.

\section{Patient 2}

A 66-year-old man, who had continuously smoked 35 cigarettes per day for 30 years, underwent surgery and radiotherapy for maxillary cancer in 1994, surgery for oropharyngeal cancer in September 2002, and surgery for tongue cancer in December 2002. Chest CT in September 2008 showed a mass $35 \mathrm{~mm}$ in diameter. Adenocarcinoma was confirmed by TBLB. He was treated by videoassisted thoracoscopic left upper lobectomy with systematic lymph node dissection. The LSPV was divided using a linear stapler. The postoperative course was uncomplicated. He was prescribed oral tegafur/uracil as adjuvant chemotherapy and followed up using enhanced CT every 6 months. Enhanced CT showed a thrombus in the stump of the LSPV 18 months postoperatively (Figure 1, B), but cerebral infarction developed on the same day. Brain herniation, pneumonia, and acute renal failure followed, and he died 19 months postoperatively.

\section{Patient 3}

A 53-year-old woman, who was a nonsmoker with no medical history, underwent right nephrectomy to treat right renal cell carcinoma in March 2005. Follow-up chest CT in March 2010 showed a nodule $14 \mathrm{~mm}$ in diameter in the left upper lobe. Adenocarcinoma was confirmed by TBLB. She was treated by video-assisted thoracoscopic left upper lobectomy with systematic lymph node 


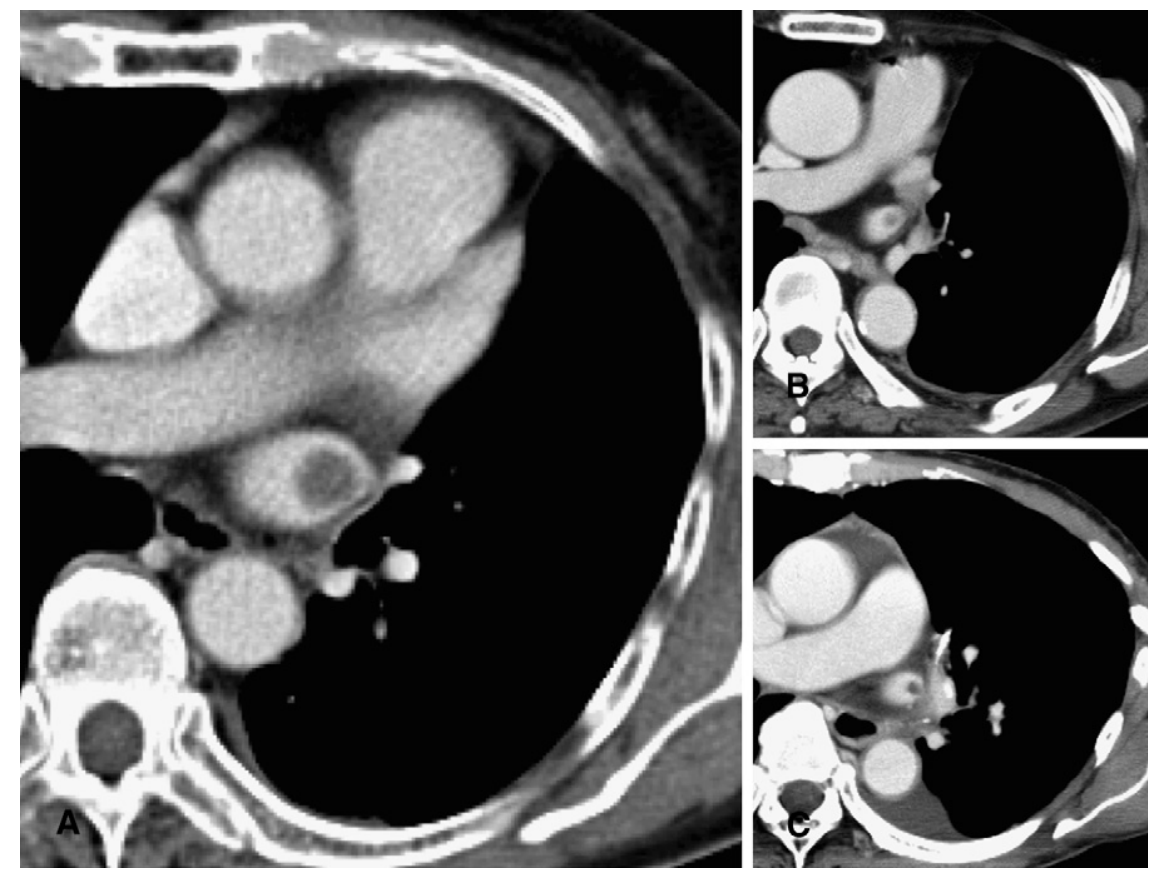

FIGURE 1. Enhanced CT shows a thrombus in the stump of the LSPV after left upper lobectomy. A, Case 1, 19 months after surgery. B, Case 2, 18 months after surgery. C, Case 3, 1 month after surgery.

dissection. The LSPV branch to the superior segment was ligated and divided, and the branch to the lingular segment was divided using a linear stapler. The postoperative course was uncomplicated. Enhanced CT for preoperative workup of ascending colon cancer showed a thrombus in the stump of the LSPV on the second postoperative month (Figure 1,C). Right hemicolectomy was accomplished, and anticoagulant therapy was immediately started. CT 6 months postoperatively showed that the thrombus had disappeared.

\section{DISCUSSION}

We described 3 patients with thrombus in the stump of the LSPV after video-assisted thoracoscopic left upper lobectomy. This is a rare complication after lung resection, but it can cause infarction of vital organs. We detected thrombi in the LSPV stump of these patients using enhanced CT before transient ischemic attack or infarction. However, cerebral infarction developed in 1 patient 9 hours after undergoing enhanced CT. The other 2 patients were administered anticoagulants and have remained free of infarction.

Only 3 case reports have described radiographically confirmed thrombus in the stump of the PV after lung resection. ${ }^{1-3}$ Three other cases of clinically suspected thrombus in the stump of the PV or left atrium have been described, but these were not radiographically proven. $^{4,5}$ Organ ischemia after left upper lobectomy developed in all 6 of these patients. Transient ischemic attack developed in 1 patient, and infarction developed in the kidneys $(\mathrm{n}=3)$, spleen $(\mathrm{n}=1)$, and external iliac artery $(\mathrm{n}=1)$. All of these patients underwent open thoracotomy. It seems unlikely that the video-assisted thoracoscopic procedure was the major cause of thrombosis.

PV thrombosis after left upper lobectomy also developed in our patients. This might be attributable to the anatomic fact that the stump of the LSPV is usually longer than that of other PVs. We measured the length of the stump of the $\mathrm{PV}$ using 3-dimensional CT in 24 patients who underwent right upper $(\mathrm{n}=5)$, right lower $(\mathrm{n}=6)$, left upper $(\mathrm{n}=10)$, and left lower $(\mathrm{n}=3)$ lobectomy. The median lengths of the stump of the right superior PV, right inferior PV, LSPV, and left inferior PV were $0.5 \mathrm{~cm}$ (range, 0.4-1.9), $0.8 \mathrm{~cm}$ (range, $0.4-0.9$ ), $2.0 \mathrm{~cm}$ (range, $1.2-2.6$ ), and $0.5 \mathrm{~cm}$ (range, 0.4-0.8), respectively. The length of the stump of the LSPV was significantly longer than those of the right superior $\mathrm{PV}$, right inferior $\mathrm{PV}$, and left inferior $\mathrm{PV}(P=.0183$, .0027 , and .0164 , respectively). Blood flow stasis in a long stump might predispose LSPV to form thrombus. Other conditions also contribute to the development of thrombus, including surgical damage to the PV endothelium and prothrombotic states, such as cancer and dehydration. Dividing the PV proximal to the pericardium would shorten the stump of the LSPV so that PV thrombus could be avoided. However, this procedure does not seem practical for all patients. Because it is difficult to prevent thrombus of the PV stump by surgical technique, it is important to detect 
thrombus promptly and start anticoagulant therapy as quickly as possible before infarction.

Thrombus in the stump of the PV after lung resection is rare; only 3 case reports have been published worldwide. However, we observed 3 cases of such thrombi in a single institution within a few years. We assumed that routine enhanced CT would show PV thrombus. We have occasionally encountered patients with a history of lung resection in whom cerebral infarction developed. This might have been caused by clinically undetectable thrombus in the stump of the PV. First, we think it is necessary to know the frequency and peak time of onset by performing periodic enhanced CT on many patients after lobectomy.

\section{CONCLUSIONS}

We described 3 patients with thrombus in the stump of the LSPV after video-assisted thoracoscopic left upper lobectomy. Periodic enhanced CT might be useful to avoid organ infarction secondary to PV thrombosis after left upper lobectomy.

\section{References}

1. Nagaoka E, Yano M, Sugano T, Miyamoto T. Thrombus in the left superior pulmonary vein after left upper pulmonary lobectomy. J Thorac Cardiovasc Surg. 2008; 135:709-10.

2. Schwalm S, Ward RP, Spencer KT. Transient ischemic attack in a patient with pulmonary vein thrombosis after left upper lobectomy for squamous cell lung cancer. J Am Soc Echocardiogr. 2004;17:487-8.

3. Seki M, Endo M, Kidani M, Kobayashi H, Sato H, Noto T. A rare case of left atrial thrombus after left upper pulmonary lobectomy [Article in Japanese]. Nippon Kyobu Geka Gakkai Zasshi. 1989;37:1371-5.

4. Asteriou C, Barbetakis N, Efstathiou A, Kleontas A, Tsilikas C. Renal artery thrombosis following lobectomy for lung cancer. Case Rep Oncol. 2010;3: 208-11.

5. Oura H, Hirose M, Aikawa H, Ishiki M. Abdominal organ infarction encountered immediately after surgery of primary lung cancer [Article in Japanese]. Kyobu Geka. 2005;58:137-42.

\title{
Delayed bleeding after transapical aortic valve implantation
}

\author{
Antonio Maria Calafiore, MD, ${ }^{\mathrm{a}}$ Adam Ibrahim, MD, ${ }^{\mathrm{a}}$ Saeed al Ahmari, MD, ${ }^{\mathrm{b}}$ Angela Lorena Iacò, MD, ${ }^{\mathrm{a}}$ and \\ Houssein Al Amri, MD, ${ }^{\mathrm{b}}$ Riyadh, Saudi Arabia
}

Bleeding from apical access early after transapical transcatheter aortic valve implantation (TAVI) is a known complication, reported in $4.8 \%$ of the patients in the TRAVERCE trial. ${ }^{1}$ A case of delayed bleeding has been reported by Masson and associates ${ }^{2}$ but it is not clear when the complication happened (weeks to months).

We herein report the case of a patient who was readmitted 10 months after a successful transapical TAVI with a pseudoaneurysm at the apical level, which, very likely, caused hemoptysis.

\section{CLINICAL SUMMARY}

An 82-year-old man underwent transapical TAVI on June 16,2010 , because of severely symptomatic aortic stenosis.

\footnotetext{
From the Departments of Adult Cardiac Surgery ${ }^{\mathrm{a}}$ and Adult Cardiology, ${ }^{\mathrm{b}}$ Prince Sultan Cardiac Center, Riyadh, Saudi Arabia.

Disclosures: Authors have nothing to disclose with regard to commercial support.

Received for publication Aug 15, 2011; revisions received Sept 13, 2011; accepted for publication Oct 3, 2011.

Address for reprints: Antonio Maria Calafiore, MD, Department of Adult Cardiac Surgery, Prince Sultan Cardiac Center, Riyadh, Kingdom of Saudi Arabia (E-mail: am.calafiore@gmail.com).

J Thorac Cardiovasc Surg 2012;143:e5-6

$0022-5223 / \$ 36.00$

Copyright $(2012$ by The American Association for Thoracic Surgery

doi:10.1016/j.jtcvs.2011.10.009
}

The Society of Thoracic Surgeons score and logistic EuroSCORE were 9.3 and 21.32, respectively. He had a systemic disease (lymphoma) that, together with diffuse calcifications of the ascending aorta, contraindicated cardiopulmonary bypass. The presence of peripheral vascular disease prevented the transfemoral approach. A No. 26 Sapien valve (Edwards Lifesciences, Inc, Irvine, Calif) was implanted transapically. His postoperative course was complicated by a transient renal impairment, but he was discharged after 11 days in good conditions. Both the chest x-ray film and echocardiogram showed no pathologic findings. Inasmuch as he was living more than $1.500 \mathrm{~km}$ away from our center, he never came to any follow-up appointment.

On June 11, 2011, he was admitted urgently because of hemoptysis, which had started 4 days earlier. A chest x-ray film showed an important opacity on the left side (Figure 1). A bronchoscopic examination, immediately performed, showed active bleeding from the lower left lobe. At this level there was a shiny lesion that easily bled if touched. A computed tomographic scan (Figure 2) showed a huge pseudoaneurysm arising from the site of the previous surgical approach, extending to the left side of the chest. The echocardiogram confirmed this finding and showed a well-functioning aortic prosthesis. The patient underwent reoperation on June 12. Cardiopulmonary bypass had to be instituted to free the previous adhesions and to control the 